\title{
Resenha
}

Nazareth Salutto' Anelise Monteiro do Nascimento 2 Silvia Neli Falcão Barbosa ${ }^{3}$

\section{A abordagem Pikler: educação infantil}

FALK, J. (org.). A abordagem Pikler: educação infantil. São Paulo: Omnisciência, 2016.

$\mathrm{P}$ ublicada originalmente em 2008 pela Associação de Mestres Rosa Sensat de Barcelona, e em 2016 com tradução para o português no Brasil, o objetivo da obra é contribuir para os interessados pelos estudos sobre os bebês e a educação de zero a três anos. Se justifica pelo reconhecimento de que os primeiros anos de vida são estruturais para o desenvolvimento do ser humano e que existe uma lacuna no campo da pedagogia para essa faixa-etária. A escolarização precoce, estampada na necessidade de um currículo que define aprendizagens específicas, nega o direito a uma relação cotidiana na qual os adultos se concentrem nas crianças e não em propostas e atividades. O que nós temos de demasiado humano é a atenção recíproca e amorosa, o que traz para a abordagem Pikler um lugar único nas propostas de educação para as crianças bem pequenas.

Essa atenção recíproca e amorosa é centro de uma pedagogia criada pela pediatra húngara Emmi Pikler, focada nas relações cotidianas de cuidado entre adultos e crianças e no movimento livre, como premissas para um desenvolvimento de qualidade, Emmi Pikler (1902-1984) foi uma pediatra que, após formar-se em medicina na cidade de Viena, começou a atuar como médica de família em Budapeste, HU, na década de 1930. A abordagem Pikler tem como base um complexo trabalho de estudo e pesquisa realizados desde 1946 em Budapeste, HU, por Emmi Pikler e seus colaboradores. Após a guerra, Emmi Pikler foi convocada a dirigir um orfanato na rua Lóczy, em Budapeste. Inicialmente o Instituto Lóczy, como foi chamado, teve como objetivo atender crianças órfãs ou abandonadas após a Segunda Guerra Mundial. Esse atendimento se estendeu até 2011. Durante esses 65 anos, mais de 2000 bebês viveram em Lóczy, a maioria tinha entre 0 e 3 anos de idade.

\footnotetext{
1 Doutora em Educação pela Pontifícia Universidade Católica do Rio de Janeiro. Professora do Ensino Superior da Universidade Federal Fluminense. E-mail: nazarethssalutto@gmail.com

2 Doutora em Educação pela Pontifícia Universidade Católica do Rio de Janeiro. Professora Adjunta da Universidade Federal Rural do Rio de Janeiro. E-mail: anelise.ufrij@yahoo.com.br

3 Doutora em Educação pela Pontifícia Universidade Católica do Rio de Janeiro. Professora da Pontifícia Universidade Católica do Rio de Janeiro. E-mail: silvianeli@yahoo.com.br
} 
Atualmente, nesse mesmo espaço funciona uma creche para crianças de 0 a 3 anos, sob a coordenação de Anna Tardos, filha de Emmi Pikler. Nos anos em que esteve à frente do Instituto, Emmi Pikler liderou estudos sobre o desenvolvimento dos bebês, bem como sobre os procedimentos que os adultos responsáveis por essas crianças deveriam ter para que esse atendimento fosse marcado pelo respeito à criança. Todo esse investimento tem como objetivo garantir o crescimento das crianças em condições físicas, psicológicas e afetivas saudáveis. O livro que agora temos em mãos fala dessa abordagem e suas concepções.

\section{O livro está dividido em seis capítulos}

Os três primeiros capítulos são escritos por Judit Falk. Em "Cuidados pessoais e prevenção", primeiro capítulo, a autora destaca aspectos da transição entre as ações de cuidado e prevenção da situação familiar para a institucionalizada (educação infantil) e enfatiza a perspectiva dos mínimos detalhes. Ao indagar "o que é boa saúde?”, a autora sugere que é preciso pensar a saúde para além dos quadros profiláticos, considerando, além do físico, outras áreas de desenvolvimento do ser humano, dando ao termo prevenção, sentido mais amplo. Isso porque, nessa abordagem, considera-se o potencial inato da criança e sua tendência ao crescimento e ao desenvolvimento. A prevenção tem sua garantia na força do papel do adulto - nos mínimos detalhes - em criar condições de equilíbrio para o desenvolvimento, seja para o bebê seja para a criança. Isto, especialmente, no que tange tomar consciência de si próprio, no vínculo de confiança estável construído com o adulto e no modo como este organiza os elementos do entorno que permitem ao bebê a constituição da sua subjetividade. O marco é o relacionamento, a relação que envolve a imitação, a assimilação e a identificcaşão e que auxilia o bebê e a criança na apropriação do sistema de valores. Situações para as quais se exigem outro status de organização nas instituições de educação infantil, uma vez que as motivações e relações dos adultos com os bebês e crianças são de natureza diferente; para $a$ educaşão das crianças pequenas que não são seus próprios filhos, não basta o senso comum, nem a espontaneidade, nem o instinto maternal, mas requer uma competência especial, um controle e supervisão continuada.

No segundo capítulo "A estabilidade por meio da continuidade e qualidade dos cuidados e das relações", Falk destaca elementos que considera relevantes no atendimento à criança nas instituições coletivas: permanência dos adultos que se ocupam das crianças; ações de cuidado de qualidade que envolvem a organização do ambiente material, social e o diálogo entre ambos, de modo a garantir segurança afetiva; cuidados que propiciem às crianças adquirirem consciência de si mesma; procura constante da manutenção do bom estado de saúde física e de bem-estar corporal da criança. Ressalta que todas essas ações devem ser contempladas conjuntamente, com o risco de não produzirem resultados se forem separadas. Como projeto de educação coletiva, esses princípios devem nortear as aspirações das instituições que recebem as crianças, de maneira a assegurar seu sentimento de continuidade de vida organizada. $O$ trabalho coletivo na instituição deve 
contemplar o ambiente material e o ambiente social encadeados, pois, num coletivo de crianças, o relacionamento adulto-criança se estabelece sobretudo no momento das refeições, do banho e dos outros cuidados corporais, situaçöes intimas e momentos privilegiados de contato e de interaçôes individuais.

"Desenvolvimento lento ou diferente" é o título do terceiro capítulo. Nele a autora faz uma crítica ao modelo de desenvolvimento comumente definido como normal, implicando na precocidade de estímulos sensoriais, gestuais, verbais com intuito de fazer com que as crianças superem o que alguns campos definem como problema, o que leva a indagar: o desenvolvimento lento ou diferente é visto com relação a quê ou a quem? $\mathrm{Na}$ abordagem Pikler os cuidados de boa qualidade e a organização do ambiente são condições que crianças, com ou sem desafios de desenvolvimento, necessitam para seu amadurecimento. A autora contrapõe à perspectiva do desenvolvimento lento a ideia de que cada bebê e criança sejam respeitados e aceitos nas suas manifestações de ritmo e tempo diante das situações que vivem e partilham. O fato de ser aceito, faz com que o bebê, na tomada de conhecimento de si, confie nas próprias condições. Assim, quanto menor a criança, mais sensivel ela se mostra aos desejos dos adultos; apesar de serem observadas, e geralmente reconhecidas, as diferenças individuais são consideradas variações pouco importantes em relação ao tipo ideal. Para Emmi Pikler, o que os bebês e as crianças precisam é de tempo, pautados numa relação mútua de confiança e intimidade decorrentes dos cuidados de boa qualidade.

Os três últimos capítulos da obra foram escritos por Anna Tardos, filha de Emmi Pikler e responsável atual pela Associação Pikler-Lóczy. Em "Autonomia e/ou dependência”, quarto capítulo, a autora coloca em xeque esses dois conceitos. Partindo do reconhecimento da importância da atividade autônoma no desenvolvimento psíquico do bebê, Tardos toma como exemplo o comportamento tradicional dos pais de sentar a criança, colocá-la de pé e farệ-la andar segurando suas mãos para indicar que, o discurso que compreende o bebê como totalmente dependente do adulto, é na verdade, um discurso que legitima uma relação de submissão entre adultos e crianças. Essa relação de submissão se dá de forma mais intensa porque, ao conceber a criança como dependente do adulto, esse supõe que sem a sua intervenção o bebê não se interessa pelo ambiente, pelo próprio corpo (...) não aprende certos movimentos. Mas as pesquisas do Instituto mostram que isso não é verdade, se confiarmos nas capacidades da criança pequena, se apoiarmos sua atividade autônoma, veremos que ela é capaz de muito mais coisas do que geralmente imaginamos, como destreza corporal e uma curiosidade atenta pelo seu ambiente. Diante dessa realidade a autora questiona $O$ desenvolvimento do bebê é autônomo ou dependente do adulto? E termina o capítulo afirmando que é preciso estabelecer qual é o lugar que a criança ocupa nessa dependência de modo que sua competência e sua capacidade de construir a si mesma tenham espaço nessa relação.

O quinto capítulo tem como título "A mão da educadora". Nele, Tardos se dedica ao papel dos estímulos táteis na vida do bebê, destacando que nem sempre o contato tátil com o adulto é agradável para a criança: um gesto brusco, ou inesperado, pode ser por exemplo, desagradável para o bebê. E acrescenta que o desconforto vem da mudança de seu equilíbrio, considerando ser fundamental que ao segurar o bebê nos primeiros anos de vida, o adulto sustente bem a sua cabeça. A questão central apontada pela autora ao 
longo desse capítulo diz respeito à preocupação de que as experiências das crianças educadas em instituições de acolbimento não são sempre tranquilas e reconfortantes, e parte desse desconforto pode se dar pela forma com que acontecem os estímulos táteis. Deste modo, os movimentos das educadoras não podem ser rápidos ou mecânicos, uma vez que a maneira como a educadora trata a criança transmite para ela muitas informações. Tardos propõe que sejam realizados movimentos ternos e delicados que expressem o interesse da educadora pela criança e que sejam guiados pela força do olhar, da palavra e do gesto.

O último capítulo "As atividades dirigidas" faz uma crítica à forma como os professores conduzem as atividades coletivas. Tendo como referência as instituições de acolhimento, o que Tardos apresenta tem relevância para a educação infantil em geral. Segundo a autora, a criança associa sentido ao objeto quando a imagem do objeto se associa com seus movimentos. Levando em consideração que as atividades dos primeiros anos constituem as condições fundamentais para a formação posterior dos conceitos de pensamento abstrato, Tardos questiona a eficácia de atividades dirigidas que retirem da criança a possibilidade de agir sobre o seu entorno. Traz como exemplo a roda de conversa, a exploração de imagens ou propostas de manipulação de objetos que exijam que todas as crianças façam a mesma coisa ao mesmo tempo, alertando que a prática da imposição de atividades que limitem a ação da criança, elimina, totalmente, a fantasia criadora, pois a criança se vê condicionada a agir de acordo com as diretrizes recebidas. Na maioria das propostas, $o$ resultado fica mais importante do que a criança. Sem desconsiderar que a criança pequena precisa do adulto para aprender certas coisas, como as regras básicas da vida comum, o capítulo termina alertando para o fato de que uma proposta centrada na competência e autonomia da criança exige um bom conhecimento da criança, muita atenção e disposição.

Salienta-se nessa obra o seu caráter didático por proporcionar uma visão específica do trabalho com a criança de zero a três anos, com orientações práticas e fundamentadas na experiência de mais de quarenta anos de trabalho cotidiano com bebês e crianças no Instituto Lóczy, de Budapeste. Numa linguagem de fácil entendimento, o livro é acessível a todos os educadores da área, oferecendo, tanto para educadores quanto para os pais/famílias/responsáveis, reflexões e caminhos para a educação dos bebês e das crianças pequenas.

Desse modo, além de se constituir como uma proposta consistente para a educação coletiva das crianças de zero a três anos, esse livro é uma forte contribuição, seja para compreender quem é o bebê e a criança pequena, como ela aprende e significa o mundo, quanto para constituição da identidade do professor que atua na educação infantil. 